\section{SIMULATION MODELING OF} THE CZECH REPUBLIC
ECONOMY WITH A
DEVELOPMENT
FORECASTING

ELENA GRESOVA ${ }^{1}$, JOZEF SVETLIK ${ }^{2}$

${ }^{1}$ Institute of Control and Informatization of Production Processes, Faculty of Mining, Ecology, Process Control and Geotechnologies, Technical University of Kosice, Kosice, Slovakia

2Department of Manufacturing Machinery and Robotics, Faculty of Mechanical Engineering, Technical University of Kosice, Kosice, Slovakia

DOI : 10.17973/MMSJ.2021_6_2021047 e-mail: jozef.svetlik@tuke.sk

The current uncertain and rapidly changing time requires a thorough analysis of the actual situation and subsequent appropriate decision-making in many areas. This applies to the individual national economies and their particular sectors, as well. Therefore, the topic of development forecasting is becoming even more important nowadays. The presented paper deals with forecasting associated to the further development of the selected national economy through modeling via simulation technique. The country of selection is the Czech Republic. The gross domestic product (GDP) is chosen as the indicator that the most reliably reflects the national economy condition. Therefore, a prediction of the potential GDP development is realized. The obtained findings are applied to the industry segment.

KEYWORDS

Development forecasting, gross domestic product, industrial sector, macroeconomic indicator, national economy, simulation modeling

\section{INTRODUCTION}

Simulation modeling concerning the different national economies is research subject of the quite extensive group of the empirical studies. The interest is focused on the economy as a complex entity or its selected part. Mostly the macroeconomic indicators are picked for analysis. We can say that the gross domestic product (GDP) reflects the economy as a comprehensive unit and it is a representative of the national economy condition.

It is a well-known fact that there is a high correlation between the development of industry segment and the development of the economy as a whole. Therefore, the positive development of the economy as a whole and thus, following the previous claim, the positive development of the GDP manifests itself as a positive development of industry and vice versa. In other words, findings including development trend pertaining to the GDP are applicable to the industrial sector, as well.

Considering our topic, the forecast realization may tend to approximate the short-term period or long-term period. Both cases are implemented by the researchers, it is not possible to clearly declare which is more preferred. Forecasting is executed by using various approaches, models and algorithms. There rises an option to combine them likewise to design a completely new one. An overview of the literature brings manifold scientific papers that confer alternatives stated above.

The paper's principal target is represented by a development prognosticating of the Czech Republic economy through modeling over a simulation utilization.

\section{LITERATURE REVIEW}

A comprehensive simulation study is offered by [Smeekes 2018] where the penalized regression methods are examined. The purpose is their application relevancy to the macroeconomic forecasting. A valuable contribution of the mentioned work lies in practical implementation to an extensive macroeconomic U.S. dataset. Macroeconomic forecasting can be found in [ $\mathrm{Li}$ 2014], too. Exploration refers to so-called LASSO-based techniques and predicting twenty key macroeconomic variables. What is more, the proof of diminution concerning the mean square forecast error by using forecasts combination of the LASSO-based approaches with dynamic factor models is stated.

Indicators belonging to the group with macroeconomic character are diverse. One of them is export. Investigation targeted to the prognosis of this indicator is presented by [Dias 2018]. Portugal is under scrutinization. Study of [Ghosh 2017] deals with the similar matter while the country in question is India. On the other hand, import is explored and forecasted in [Grimme 2021]. Both referred macro indicators are predicted by [Ersen 2019].

The most commonly used measure of the economy is GDP. Forecasting GDP is subject of concern for [Dias 2017]. The estimation for forecasting manner of the factor models with aim to prognosticate some GDP integrants is pursued as well as the efficiency of a bottom-up approach to appraise the GDP growth. The GDP growth assessment resolve also [Jeric 2020]. Authors focus specifically on the quality inspection of the GDP growth forecasts over multiple forecasters. Defined dataset includes statistics for 6 separate institutions.

There exist multiple points of view when forecasting GDP. [Angelini 2011] put emphasis on the short-term GDP predictions, [Madhou 2020] publish GDP foretelling for a small open developing economy, [Cepni 2019] are oriented on the emerging markets, [Tacchella 2018] provide look on a dynamical systems conception in the context of GDP forecasting or [Guerard 2020] deal besides GDP with unemployment alike as some additional economic markers.

Modeling by utilizing the newly designed framework represents a special category. For instance, [Kuang 2017] discuss a novel macroeconomic forecasting model which is grounded on the revised multimedia assisted BP neural network standard and also the ant colony algorithm. Two major matters are highlighted - uncertainty within prediction approach in the connection with choice mistakes and restrictions of the prediction approach. Next academic paper giving a new kind of model is [Wu 2019]. They construct the nonlinear grey Bernoulli model that underlies the optimization. Noticed model serve for China's GDP prognosis making. Exactness of the forecast resulting from the suggested model type is tested by using particular simulations. Moreover, the practical implementation is contained as well as estimate GDP in China for period 2019-2023. Researchers [Liu 2020] bring an upstart grey forecasting model in the company of time power term to 
forecast GDP. As in the previous case, China's GDP is a desired objective.

\section{DATA AND METHODS}

Predictions realization may be apprehended as a substantial activity for various government institutions such as treasury departments/ministries or central banks. This claim suits also for the international organizations, for example the World Trade Organization [WTO 2021], the Organisation for Economic Co-operation and Development [OECD 2021], the World Bank [WB 2021], the European Bank for Reconstruction and Development [EBRD 2021] or the International Monetary Fund [IMF 2021].

Our research is based primarily on the OECD data. Database provided by this organization is characterized by complexity and coherency. We use selected statistics, reports, projections and outlooks (e.g. [OECD 2020]). National sources are the Czech Statistical Office [CZSO 2021] likewise the Czech National Bank [CNB 2021]. All sorts of collected numerical information serve us for building the dataset which is the fundament in the association with entire further analysis. Each processed data is public and freely available. According to the resources, it is the most up to date, too. The annual data are applied for our chosen variables.

The main aim of this paper is forecast execution related to further development of the selected national economy by modeling through using simulation approach. GDP is chosen as the indicator that the most reliably represents the national economy. Thus, an estimation of the potential GDP development is carried out. The investigation is focused explicitly on the Czech Republic. Prognosis covers year 2021.

Detailed specification of the GDP gives a nominal value, market prices. The unit is Czech Koruna (CZK billion). We pick 4 variables for our analysis which form the GDP. These are as follows:

- private final consumption expenditure,

- government final consumption expenditure,

- gross capital formation,

- net exports of goods and services.

Detailed specification of the first and second variable gives a nominal value, GDP expenditure approach. For the third one, it fits a nominal value, total and for the last one a nominal value, national accounts basis. The unit is the same for every mentioned variable and the identical as in the GDP condition Czech Koruna (CZK billion).

We decide to model the Czech national economy over a simulation approach. Therefore, our model is executed by a simulation when the special computer program is putted into

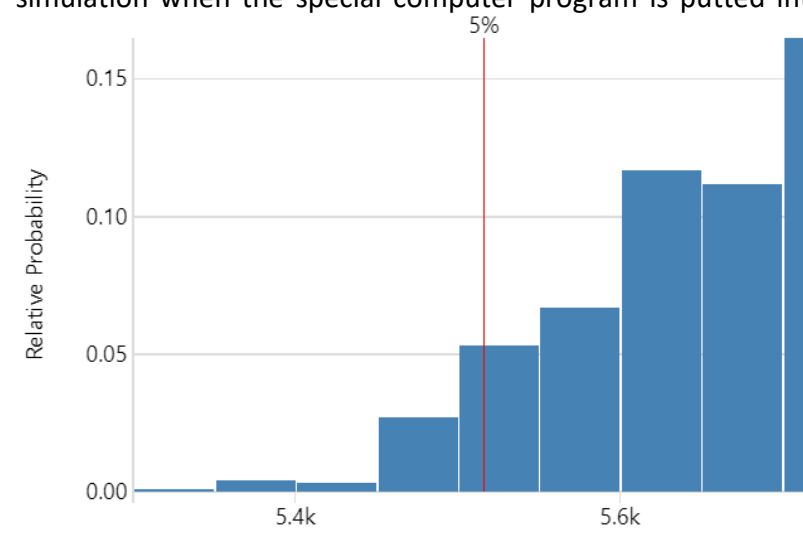

effect that passes information about the system being explored. More precisely, we reach for the particular add-in software linked to Excel which offers extra features and functions in the connection with simulations. It should be noted that we pursue together a thousand iterations.

\section{RESULTS}

Data from the stated sources, especially provided by the OECD databases, serves us for defining 3 different scenarios:

- realistic,

- optimistic,

- pessimistic.

These are formulated separately for private final consumption expenditure, government final consumption expenditure, gross capital formation and net exports of goods and services, hence, for 4 variables that we choose to step into our modeling. The announced scenarios are set for 2021 which represents our targeted year in forecasting. All 3 scenario alternatives pertaining to all 4 selected variables (12 settings) enter our simulation. Adjusting an optimistic scenario means an increase of $10 \%$ compared to a realistic one, and conversely adjusting a pessimistic scenario brings a $10 \%$ reduction compared to a realistic one.

We run the simulation pursuant to optimistic (max), realistic (likely) as well as pessimistic ( $\mathrm{min}$ ) scenario. The results are shown in Fig. 1.

Next Tab. 1 is definitely worth mentioning, whereas the key statistics are described there.

\begin{tabular}{|c|c|}
\hline Statistics & GDP \\
\hline Mean & 5737.798392140226 \\
\hline Standard Deviation & 133.8689232852464 \\
\hline Variance & 17920.888621551192 \\
\hline Skewness & 0.02719337479316698 \\
\hline Kurtosis & 2.6033423857440403 \\
\hline Mode & 5736.741041122396 \\
\hline Minimum & 5343.894264413994 \\
\hline Maximum & 6108.70854231112 \\
\hline Range & 764.814277897126 \\
\hline
\end{tabular}

Table 1. Statistics belonging to the accomplishment of the specified simulation

Tab. 1 contains the values gained through the simulation. We highlight the crucial figures - mean, minimum, maximum.

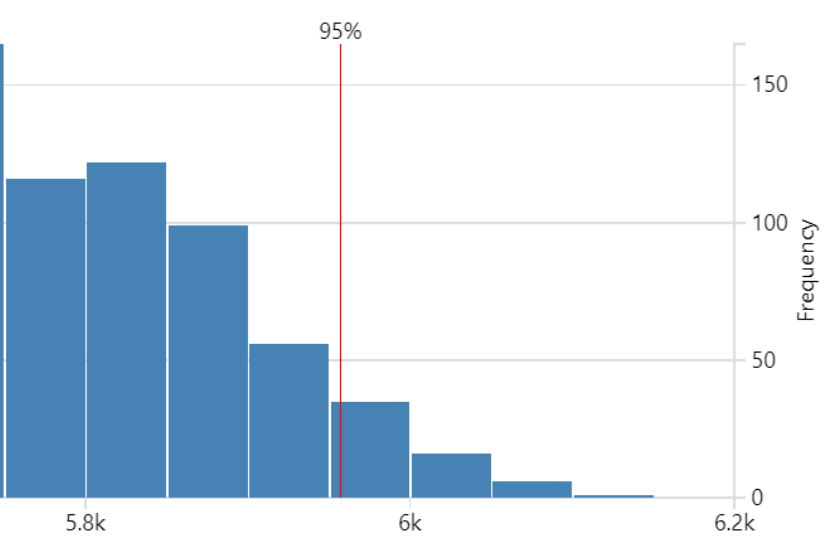


Figure 1. The results of our simulation modeling

The very explicit outcome of our modeling by utilizing simulation approach is reported in Tab. 2 . The exact GDP values are expressed according to the individual percentiles.

\begin{tabular}{|c|c|}
\hline Percentiles & GDP \\
\hline $2 \%$ & 5475.374950882345 \\
\hline $4 \%$ & 5507.648563594444 \\
\hline $6 \%$ & 5529.110218082602 \\
\hline $8 \%$ & 5543.388548419946 \\
\hline $10 \%$ & 5559.6250056641165 \\
\hline $12 \%$ & 5580.839579131509 \\
\hline $14 \%$ & 5590.990526844713 \\
\hline $16 \%$ & 5602.798681704275 \\
\hline $18 \%$ & 5611.91653303597 \\
\hline $20 \%$ & 5620.928827768452 \\
\hline $22 \%$ & 5627.262599864632 \\
\hline $24 \%$ & 5636.915998859593 \\
\hline $26 \%$ & 5647.682860158987 \\
\hline $28 \%$ & 5653.17664388806 \\
\hline $30 \%$ & 5660.752242908634 \\
\hline $32 \%$ & 5668.573473330833 \\
\hline $34 \%$ & 5677.311575493838 \\
\hline $36 \%$ & 5688.481467834931 \\
\hline $38 \%$ & 5699.3904194836805 \\
\hline $40 \%$ & 5705.985774683124 \\
\hline $42 \%$ & 5709.695668542628 \\
\hline $44 \%$ & 5715.894289347863 \\
\hline $46 \%$ & 5721.972536779021 \\
\hline $48 \%$ & 5727.729506754016 \\
\hline $50 \%$ & 5732.563494484022 \\
\hline $52 \%$ & 5737.959844928135 \\
\hline $54 \%$ & 5747.496092420658 \\
\hline $56 \%$ & 5754.47385279487 \\
\hline $58 \%$ & 5759.671489017953 \\
\hline $60 \%$ & 5769.5577141766325 \\
\hline $62 \%$ & 5779.26872721719 \\
\hline $64 \%$ & 5789.681135780389 \\
\hline $66 \%$ & 5796.086429911258 \\
\hline $68 \%$ & 5805.126318690712 \\
\hline $70 \%$ & 5812.67015037407 \\
\hline $72 \%$ & 5819.486035627492 \\
\hline $74 \%$ & 5827.246365227562 \\
\hline $76 \%$ & 5837.751665322782 \\
\hline $78 \%$ & 5844.940877263097 \\
\hline $80 \%$ & 5856.7605592470445 \\
\hline
\end{tabular}

\begin{tabular}{|cc|}
\hline $82 \%$ & 5867.932898452517 \\
\hline $84 \%$ & 5877.4401641005925 \\
\hline $86 \%$ & 5889.42659602502 \\
\hline $88 \%$ & 5897.702465914392 \\
\hline $90 \%$ & 5916.8496216604235 \\
\hline $92 \%$ & 5930.7356687183465 \\
\hline $94 \%$ & 5947.767552285374 \\
\hline $96 \%$ & 5974.5563083103625 \\
\hline $98 \%$ & 6003.434063066798 \\
\hline
\end{tabular}

Table 2. Findings resided to the GDP accompanied with attributed percentiles after simulation running

As it can be seen, some numbers are accentuated in Tab. 2. We mark them in red because we presume this data an extra interesting and we intend to pay more attention to them. In addition, their following description and interpretation serve for the other results explanation from Tab. 2.

The first one is tenth percentile. In this case the GDP value is almost the same as in 2020 . Such a finding implies that in $90 \%$ of our simulated values we obtained a value higher than in 2020. Thus, we can say that, based on our simulation, up to 90\% the year 2021 should be a better considering the GDP development than the year 2020 .

The fiftieth percentile represents a median, in fact. This signifies that $50 \%$ of the simulated results are larger than the corresponding number and at the same time $50 \%$ are smaller.

Another engaging outcome is the ninetieth percentile. It is true that only $10 \%$ of the simulation results are larger than the given value. Therefore, there exists only a $10 \%$ chance that the GDP for 2021 will be higher than this number.

Last but not least, it is worth referencing the ninety-eighth percentile. It is appropriate to claim that there is a little more than a $2 \%$ chance that the GDP of the Czech Republic will be more than 6000 billion CZK in 2021.

\section{CONCLUSIONS}

Forecasting at the macroeconomic level is a highly significant part of the research conduction. This applies for an academic sphere as well as practice. It represents one of a crucial preconditions for decision making that interfere in many areas and sets their further direction.

The position of GDP is the most important among the various macro indicators. Mentioned marker constitutes a key participant in assessment of the country's economy. It can be said that GDP growth rate demonstrates the growth of the national economy alike as national strength to a high degree. Therefore the question of GDP prognosis is greatly actual and relevant.

Indicator GDP reflects the amount of values pertaining to all final products and services in an individual national economy for a stated time period. Thus, the outcomes relating to particular sectors of the country's economy are included. Integral and eminently decisive element is an industry sector.

According to the empirical studies likewise as practice itself, it may be claimed that there exists a direct proportion between 
development trend of the national economy and development trend of the industry. Therefore, we can apply conclusions concerning the GDP for the segment of industry.

The principal objective of the paper represented forecasting linked with next development of the Czech Republic economy over simulation modeling. The GDP was determined as the most credible indicator giving a picture about national economy. Conclusively, the GDP development prediction was in the center of interest.

For the purposes of the GDP forecasting, we selected several variables which constitute mentioned indicator. Specifically, private final consumption expenditure, government final consumption expenditure, gross capital formation and net exports of goods and services.

In our paper, we performed the simulation with the aim of a prediction - prediction of the possible levels of the GDP development. A great advantage of our research is the fact that the result gained by our simulation was not just one number.

Hence, as we state above, our findings contained prognosis of the certain levels pertaining to the GDP indicator. In other words, we evaluated the future development of the GDP with some probability or otherwise, we predicted the intervals of possible development of the GDP with a certain probability.

Our result is actually a probability distribution and, indeed, we can appreciate our predicted values with the certain values of probabilities. We perceive such a kind of the investigation outcome as highly positive. This applies also in the relation to the forecasts made by different organizations operating globally. An example is the comparison with the forecasts from the OECD. Only one exact number is always offered.

Tab. 2 brings the particular results in the context of the GDP values after running our simulation. We would like to highlight the most important findings. From the overall point of view, it can be concluded that there will be the recovery of the national economy of the Czech Republic, GDP growth, and positive developments also in the industry for 2021. We thus expect a new momentum and an optimistic trend for the industry discussing the year 2021.

The future directions of research can be focused on a similar analysis conducted for the other countries and their national economies. Such a step offers further possibilities, for instance a mutual comparison of the reached findings pertaining to individual countries.

\section{ACKNOWLEDGMENTS}

This work was supported by the Slovak Research and Development Agency under Contract no. APVV-18-0413.

\section{REFERENCES}

[Angelini 2011] Angelini, E., et al. Short-term forecasts of euro area GDP growth. The Econometrics Journal, 2011, 14(1), pp C25-C44.

[Cepni 2019] Cepni, O., et al. Nowcasting and forecasting GDP in emerging markets using global financial and macroeconomic diffusion indexes. International Journal of Forecasting, 2019, 35(2), pp 555-572.

[CNB 2021] CNB. The Czech National Bank, 2021, [online]. Available from $<$ https://www.cnb.cz/en/>.
[CZSO 2021] CZSO. The Czech Statistical Office, 2021, [online]. Available from <https://www.czso.cz/csu/czso/home>.

[Dias 2018] Dias, F., et al. Forecasting exports with targeted predictors. Banco de Portugal Economic Studies, 2018, 4(2), pp 45-62.

[Dias 2017] Dias, F., et al. A bottom-up approach for forecasting GDP in a data-rich environment. Applied Economics Letters, 2017, 25(10), pp 718-723.

[EBRD 2021] EBRD. The European Bank for Reconstruction and Development, 2021, [online]. Available from <https://www.ebrd.com/home>.

[Ersen 2019] Ersen, N., et al. The forecasting of the exports and imports of paper and paper products of Turkey using Box-Jenkins method. Eurasian Journal of Forest Science, 2019, 7(1), pp 54-65.

[Ghosh 2017] Ghosh, S. Forecasting exports of tea from India: Application of Arima model. Journal of Commerce and Trade, 2017, 12(2), pp 116-129.

[Grimme 2021] Grimme, C., et al. Forecasting imports with information from abroad. Economic Modelling, 2021, 98(5), pp 109-117.

[Guerard 2020] Guerard, J., et al. Automatic time series modeling and forecasting: A replication case study of forecasting real GDP, the unemployment rate and the impact of leading economic indicators. Cogent Economics and Finance, 2020, 8(1), pp 1759483.

[IMF 2021] IMF. The International Monetary Fund, 2021, [online]. Available from <https://www.imf.org/en/Home>.

[Jeric 2020] Jeric, S., et al. Analysis of forecasts of GDP growth and inflation for the Croatian economy. Economic Research-Ekonomska Istrazivanja, 2020, 33(1), pp 310-330.

[Kuang 2017] Kuang, Y., et al. A novel macroeconomic forecasting model based on revised multimedia assisted BP neural network model and ant Colony algorithm. Multimedia Tools and Applications, 2017, 76(18), pp 18749-18770.

[Li 2014] Li, J. and Chen, W. Forecasting macroeconomic time series: LASSO-based approaches and their forecast combinations with dynamic factor models. International Journal of Forecasting, 2014, 30(4), pp 996-1015.

[Liu 2020] Liu, C., et al. Application of a novel grey forecasting model with time power term to predict China's GDP. Grey Systems: Theory and Application, 2020, ahead-of-print.

[Madhou 2020] Madhou, A., et al. Forecasting the GDP of a small open developing economy: An application of FAVAR models. Applied Economics, 2020, 52(17), pp 1845-1856.

[OECD 2020] OECD. OECD Economic Outlook, Volume 2020 Issue 2, No. 108, OECD Publishing, Paris, 2020, [online]. Available from <https://www.oecdilibrary.org/economics/oecd-economicoutlook/volume-2020/issue-2_39a88ab1-en>.

[OECD 2021] OECD. The Organisation for Economic Cooperation and Development, 2021, [online]. Available from <http://www.oecd.org/>. 
[Smeekes 2018] Smeekes, S. and Wijler, E. Macroeconomic forecasting using penalized regression methods. International Journal of Forecasting, 2018, 34(3), pp 408-430.

[Tacchella 2018] Tacchella, A., et al. A dynamical systems approach to gross domestic product forecasting. Nature Physics, 2018, 14(8), pp 861-865.

[WB 2021] WB. The World Bank, 2021, [online]. Available from <https://www.worldbank.org/en/home>.

\section{CONTACTS:}

Ing. Elena Gresova, PhD.

Technical University of Kosice

Faculty of Mining, Ecology, Process Control and Geotechnologies Institute of Control and Informatization of Production Processes Bozeny Nemcovej 3, 04200 Kosice, Slovakia

e-mail: elena.gresova@tuke.sk

prof. Ing. Jozef Svetlik, PhD.

Technical University of Kosice

Faculty of Mechanical Engineering

Department of Manufacturing Machinery and Robotics

Letna 9, 04200 Kosice, Slovakia

e-mail: jozef.svetlik@tuke.sk
[WTO 2021] WTO. The World Trade Organization, 2021, [online]. Available from <https://www.wto.org/>.

[Wu 2019] Wu, W.Z., et al. A novel optimized nonlinear grey Bernoulli model for forecasting China's GDP. Complexity, 2019, vol. 2019, Article ID 1731262, pp 10. 